\title{
Kinematic controls on the geometry of the preserved cross sets
}

\author{
Vamsi Ganti, ${ }^{1,2}$ Chris Paola, ${ }^{3}$ and Efi Foufoula-Georgiou ${ }^{1}$ \\ Received 7 January 2013; revised 13 June 2013; accepted 19 June 2013; published 24 July 2013.
}

[1] The geometry of sedimentary strata records the dynamics of the surfaces that produced them. Cross strata are one of the most common features preserved in the stratigraphic record and are typically formed by migrating ripples, dunes, and bars. Cross-stratal geometry depends on the movement and shape of the bed forms. In this study, we provide theoretical relationships that map the statistics of surface kinematics and geometry of migrating bed forms into the 2-D geometrical structure of the preserved stratigraphy. The surface kinematics is characterized by the migration (translation of the waveforms) and deformation (change in shape of the waveforms) of the bed forms. We show that, for transverse, unidirectional bed forms, the local slope and curvature of the preserved stratigraphic boundaries depend on the competition between migration and deformation of the bed forms. Further, we show that deformation is the sole cause of curved cross-set boundaries and define a quantitative relationship between the curvature of the bounding surfaces of the preserved cross sets and the deformation rate of the bed forms. The theoretical results compare well with experimental data of subaqueous, transverse bed form evolution under equilibrium, steady state conditions with no net deposition.

Citation: Ganti, V., C. Paola, and E. Foufoula-Georgiou (2013), Kinematic controls on the geometry of the preserved cross sets, J. Geophys. Res. Earth Surf., 118, 1296-1307, doi:10.1002/jgrf.20094.

\section{Introduction}

[2] Sedimentary strata represent the primary record of past environmental conditions (e.g., climate, tectonics, sea level) and paleolandscape dynamics. In the absence of postdepositional deformation, the geometry of physical stratification is determined by sequential surface topography and subsidence. The former can be partitioned into two components: morphology and motion (kinematics). At any fixed location, the kinematics of surface topography can further be expressed in terms of a mean motion (given by the net depositional rate) and the variability around this mean (governed mainly by changing surface topography). Thus, the geometry of physical stratification is a function of three characteristics of depositional systems: (1) the geometry of surface topography, (2) the kinematics of topographic

This article was published online on 24 July 2013. Some text has been changed to reflect the wording in Martin and Jerolmack [2013]. This notice is included in the online and print versions to indicate that both have been corrected on 6 September 2013.

${ }^{1}$ Department of Civil Engineering, National Center for Earth-surface Dynamics, St. Anthony Falls Laboratory, University of Minnesota, Minneapolis, Minnesota, USA.

${ }^{2}$ Now at Division of Geological and Planetary Sciences, California Institute of Technology, Pasadena, California, USA.

${ }^{3}$ Department of Earth Sciences, National Center for Earth-surface Dynamics, St. Anthony Falls Laboratory, University of Minnesota, Minneapolis, Minnesota, USA.

Corresponding author: V. Ganti, Division of Geological and Planetary Sciences, California Institute of Technology, MC 170-25, 1200 E. California Blvd., Pasadena, CA 91125, USA. (vganti@caltech.edu)

(C)2013. American Geophysical Union. All Rights Reserved. 2169-9003/13/10.1002/jgrf.20094 change, and (3) the rate of net deposition [Paola et al., 2009; Sheets et al., 2002, 2007, Strong and Paola, 2008]. As all three of these properties are influenced by environmental conditions, the geometry of physical stratification contains information that can be used to quantitatively reconstruct paleolandscape dynamics across a range of time and space scales [Ager, 1973; Paola, 2000; Allen, 2008].

[3] Of the structures present in the physical stratigraphic record, cross-stratified units formed by migrating bed topography are among the most commonly observed. For example, transverse features such as dunes and ripples migrating on a bed leave a distinct stratal signature owing to variations in particle size distribution and fabric over the bed forms and because local scour during bed form passage produces erosional surfaces that are preserved in the stratigraphic deposits [e.g., Sorby, 1859, 1908, Allen, 1963a, 1963b, 1968, 1970; Brookfield, 1977; Hunter, 1977a, 1977b, Rubin and Hunter, 1982; Rubin, 1987; Paola and Borgman, 1991; Anderson and Bunas, 1993; Makse, 2000; Leclair, 2002; Blom et al., 2003; Jerolmack and Mohrig, 2005]. The preserved deposit between two successive erosional surfaces is called a cross set or a cross-stratified unit. The crossstratification patterns depend on the movement of the bed forms, including any changes in shape and/or direction of travel of the bed forms [e.g., Allen, 1973]. Since geometrical measures of dune cross strata (e.g., set thicknesses) can be related to the water depth at the time of deposition [e.g., Yalin, 1964; Allen, 1970], data from such deposits can be used to reconstruct paleochannel depth and width [Bridge and Tye, 2000].

[4] The relationship between the geometry of bed forms and associated cross stratification has been a subject of 

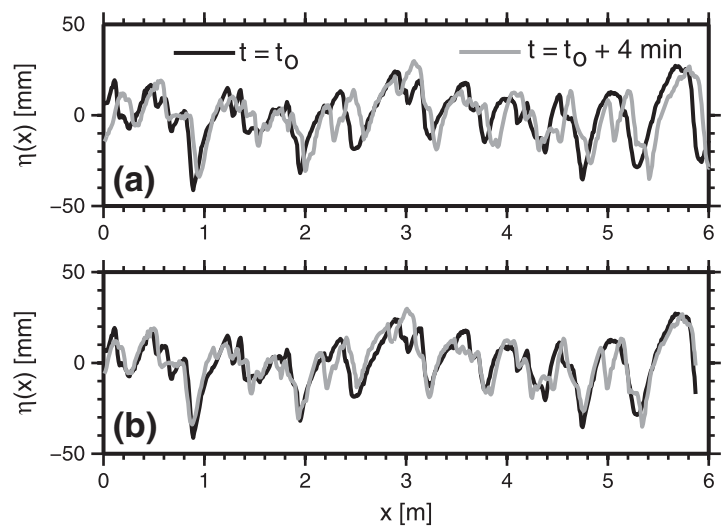

Figure 1. (a) Two superimposed streambed profiles from the experimental data set corresponding to the $80 \mathrm{~L} / \mathrm{s}$ water discharge. The gray profile is from $4 \mathrm{~min}$ after the black profile. Notice that the initial streambed profile has translated and deformed over time. (b) This deformation becomes more evident after accounting for the mean migration component by shifting the gray profile backward along the longitudinal axis.

qualitative [e.g., Allen, 1970, 1973] and quantitative analysis for many years [e.g., Rubin and Hunter, 1982; Paola and Borgman, 1991; Bridge and Best, 1997; Leclair et al., 1997; Leclair and Bridge, 2001; Leclair, 2002; Jerolmack and Mohrig, 2005]. The geometry of cross-stratified units includes the distribution of set thicknesses and measures of the length and shape of the cross sets. Of these, the most studied variable in the literature is the set thickness. Paola and Borgman [1991] developed a theoretical relationship that maps the variability of the bed form heights into the distribution of the set thicknesses under zero net depositional conditions. Bridge and Best [1997] extended this theory to the case where net deposition occurs, developing an empirical relationship between the mean set thickness and the bed form geometry and net aggradation rate. Several experimental studies validated the Paola-Borgman and the modified Paola-Borgman theories and quantified the role of net aggradation rate and variability in subaqueous bed form heights in controlling the set thicknesses [Leclair et al., 1997; Storms et al., 1999; Leclair and Bridge, 2001; Leclair, 2002]. Further, via a numerical model for subaqueous bed form evolution, Jerolmack and Mohrig [2005] highlighted the importance of the competition between net aggradation rate and bed form migration rate on the resulting distribution of set thicknesses. Controls on the length of the cross sets were studied qualitatively [Allen, 1973] and quantitatively using experimental data [Leclair, 2002]. Allen [1973] found that the length of bounding surfaces of cross sets formed by current ripples is about half the bed form wavelength, which was later experimentally validated for dunes by Leclair [2002].

[5] Almost all studies to date have focused on the effect that migration and aggradation rates have on the geometry of the cross sets. Although change in shape of the bed forms as they migrate has been thought to have an effect on the geometry of the cross sets as early as the work of Allen [1973], very little quantitative or experimental insight has been developed in this respect. In a recent major advance, McElroy and Mohrig [2009] show that the change in shape of the evolving, subaqueous bed forms can be quantified by comparing a vertical bed-surface deformation rate to a characteristic bed form migration rate. The focus of our study is to understand the effect of this deformation rate on cross-set geometry and to develop theoretical relationships between the surface kinematics of bed form evolution and the geometrical structure of the cross sets, in particular, the slope and curvature of the cross-set boundaries.

[6] This paper is structured as follows. In the next section, we develop the theoretical relationships between the slope and curvature of the bounding surfaces of the preserved cross sets in terms of the surface kinematics of bed form evolution. In section 3 , we describe the experimental setup and data on bed form evolution used in this study. Analyses for characterizing the surface kinematics of bed form evolution and the geometrical structure of the preserved stratigraphy for the experimental data are presented in sections 4 and 5, respectively. In section 6 , we test the proposed theoretical relationships between surface kinematics of bed form evolution and the geometrical structure of the preserved stratigraphy using experimental data collected under zero net depositional conditions. Finally, we present discussion and conclusions in sections 7 and 8 , respectively.

\section{Theoretical Development}

[7] Consider a train of bed forms whose 1-D elevation profile in the streamwise direction $x$ as it evolves over time $t$ is given by $\eta(x, t)$. The surface kinematics of this train of bed forms can be characterized in terms of the rate of migration of the bed forms and the change in shape of the bed forms as they migrate (see Figure 1). McElroy and Mohrig [2009] developed a unifying theoretical framework to investigate the evolution of sandy bed forms. They proposed that the bed is appropriately described by a kinematic wave with a source term given by

$$
\frac{\partial \eta(x, t)}{\partial t}+V_{c} \frac{\partial \eta(x, t)}{\partial x}=\Pi(x, t)
$$

where $V_{c}$ is the characteristic bed form migration rate and $\Pi$ is the deformation rate, which is a vertical velocity. When $\Pi=0$, the above equation describes the case of evolving bed forms that are translationally invariant, whereas $\Pi>0$ describes the case of a locally aggrading bed, and $\Pi<0$ describes the case of a locally eroding bed. McElroy and Mohrig [2009] noted that the dynamic bed evolution, as defined by equation (1), can be used to infer the features preserved in the stratigraphic record. Namely, this equation can be used to quantify the effect of bed form deformation on the geometry of the preserved strata.

[8] The deformation rate, as defined above, includes bed form change due to changing flow conditions as well as internally generated changes of bed form shape (as in Figure 1b) and net deposition that leads to climbing bed forms. Thus, the deformation rate, as defined by McElroy and Mohrig [2009], can produce strata that record the whole range of behaviors from the steady aggradation of Rubin and Hunter [1982] to the bed form variability described by Allen [1973] and Paola and Borgman [1991]. Our interest here is to use the above definition of dynamic bed evolution to understand the effect that the change in shape of the subaqueous bed forms has on the geometry of preserved cross sets. For this purpose, we decompose the deformation rate 
into two components: (a) a mean aggradation rate that quantifies any systematic rise or fall in the spatially averaged bed level $(\bar{r})$, and (b) change in shape of the bed forms as quantified by the short-time variations around an equilibrium profile $(\pi)$. Under this decomposition, the short-time variations around an equilibrium profile average out to be zero over some time scale (i.e., $\langle\pi\rangle_{t}=0$, where $\langle$. $\rangle$ denotes the average of the quantity within the angled brackets).

[9] Since the deformation rate is a velocity that describes the vertical rate of change in bed elevation, the slopes of the bounding surfaces of the cross sets are given by (Figure 2a)

$$
S_{s t}=\frac{\Pi}{V_{c}}=\frac{\bar{r}}{V_{c}}+\frac{\pi}{V_{c}}
$$

This relationship was established as early as the works by Allen [1970] and Rubin and Hunter [1982] but including only the first term on the right: the angle of climb of the bed forms was defined as the ratio of the vertical aggradation rate to the horizontal, streamwise celerity. The above definition gives us further insight in that the first component of the slope of the bounding surfaces results from the constant net aggradation present in the system, which results in a constant slope of the bounding surfaces. The second component in the above equation is a stochastic quantity that is zero on average but can result in local changes of the slope of the bounding surface. Spatial changes in the local slope of the bounding surfaces result in curved bounding surfaces.

[10] Specifically, the spatial rate of change of the slope of the bounding surface is the curvature of the bounding surface. Thus, we can derive the curvature of the bounding surfaces from equation (2) as

$$
C_{s t}=\frac{\partial S_{s t}}{\partial x}=\frac{\partial}{\partial x}\left(\frac{\Pi}{V_{c}}\right)=\frac{\partial}{\partial x}\left(\frac{\bar{r}}{V_{c}}+\frac{\pi}{V_{c}}\right)
$$

where $C_{s t}$ is the curvature of the bounding surfaces of the cross sets (Figure 2b). From the above equation, we note that curved bounding surfaces can result from changes in net aggradation rate, migration rate, and bed form deformation rate. In the case when the characteristic migration rate and the net aggradation rate are constant, the curvature of the bounding surfaces of the preserved cross sets is given by

$$
C_{s t}=\frac{1}{V_{c}} \frac{\partial \pi}{\partial x}
$$

where $\pi$ corresponds to the short-time variations around an equilibrium bed profile and quantifies the change in shape of the bed forms. Further, equation (3) implies that translationally invariant bed forms do not produce curved bounding surfaces under constant net aggradation rate. We note that the theoretical relationships of equations (2) and (4) are applicable for transverse bed forms that do not have significant along-crest transport. This condition allows for the one-dimensional simplification made in our study.

[11] Further, inherent to the above derivation is the time scale of applicability of these relationships. The bounding surfaces of the cross sets are formed over a time scale that corresponds to the time needed for a single bed form to translate a distance of the order of its own length or greater, and thus the migration and deformation rate should be computed over that time scale, as discussed in section 4 . In the next section, we describe experimental data of bed form evolution collected under zero net deposition, in which case the deformation rate comprises only the short-time variations corresponding to the change in the shape of the bed forms $(\Pi=\pi)$. We used these data throughout the paper to demonstrate and test the proposed theory.

\section{Experimental Arrangement and Data Collected}

[12] The experiments reported in this section were conducted during the summer of 2011 in the Tilting Bed Flume at the Saint Anthony Falls Laboratory (SAFL) at the University of Minnesota, Minneapolis [Martin and Jerolmack, 2013]. The dimensions of the flume are as follows: length of $15.0 \mathrm{~m}$, width of $0.92 \mathrm{~m}$ and depth of $0.65 \mathrm{~m}$. The bed of the flume was adjusted to zero slope $\left( \pm 10^{-4}\right)$. Sand grain sizes were measured using a Retsch Camsizer and well characterized by a lognormal distribution. The median grain diameter was $D_{50}=0.37 \mathrm{~mm}$ and the 10th and 90th percentiles of the grain size were $D_{10}=0.25 \mathrm{~mm}$ and $D_{90}=0.58 \mathrm{~mm}$, respectively. Measured sand density and the measured surface bed sediment volume fraction were $\rho_{s}=2.60 \mathrm{~g} / \mathrm{mL}$ and $\phi=0.58$, respectively.

[13] Water from the Mississippi River entered the flume through a large pipe submerged in an upstream headbox and exited the flume into a discharge channel via a free overfall. Water discharge was controlled manually by a hydraulically actuated valve and was measured using a linear calibration curve relating valve pressure to water discharge. The discharge calibration curve was determined by filling large weighing tanks for known durations of time for a range of six discharges. Uncertainties in the calibration curve and the head variations at the inlet water source induce an uncertainty in reported discharges that is about $\pm 4 \%$.

[14] We maintained a roughly constant volume of sand in the flume using a recirculating pump. A minimum depth of sediment was ensured in the flume using a $20 \mathrm{~cm}$ high wall, which was downstream of the test section. The downstream sand flux overtopping this wall settled into a submerged funnel, which was located $14 \mathrm{~m}$ downstream of the headbox. A water jet carried this overtopped sediment back to the upstream end of the flume, which was then released back evenly across the channel cross-section through a manifold. The discharge of the pump as measured via a broad-crested weir was $13.3 \pm 1.1 \mathrm{~L} / \mathrm{s}$. Water for the eductor jet was drawn directly from the headbox of the flume; thus, the only addition of water discharge generated by the flume was that created by suction of water into the settling funnel, which we could not measure but believe to be small. A minimum flow depth was maintained within the flume using a $26 \mathrm{~cm}$ high gate, which was downstream of the collection funnel that prevented the formation of lateral instabilities and braiding.

[15] Unsteadiness in water flow from the headbox was smoothed by forcing flow through a mesh of cobbles. A matrix of upright PVC pipes downstream of the recirculation manifold also helped to straighten the flow (see Figure 3), and a float on the water surface smoothed out surface disturbances. However, a zone of sediment scour formed that extended to about $3 \mathrm{~m}$ downstream of the headbox. Thus, we limited our bed form analysis to a zone from 5 to $13 \mathrm{~m}$ downstream of the flume headbox.

[16] The bed topography was measured during the experiments by successive sonar scans using a JSR Ultrasonic 

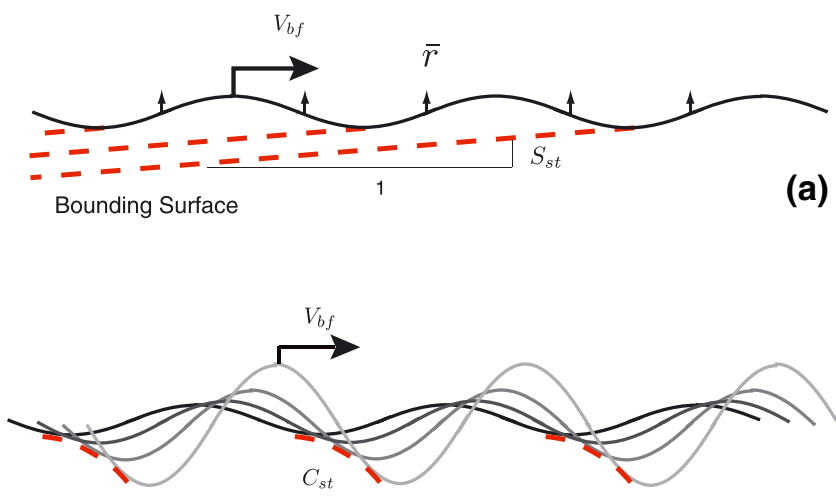

(b)

Figure 2. Schematic highlighting the role of deformation of bed forms in the formation of stratigraphic bounding surfaces (red dashed lines). (a) Translationally invariant bed forms under constant net deposition $(\bar{r})$ and migration rates $\left(V_{b f}\right)$ produce straight set boundaries with a slope $S_{s t}$. (b) However, when the bed forms change in shape during their evolution, then the resulting stratigraphic boundaries have a curvature $\left(C_{s t}\right)$ owing to the local changes in the slope of the bounding surface.

DPR300 Pulser/Receiver. The sonar was submerged about $1 \mathrm{~cm}$ below the water surface to minimize flow disturbances and it swept up and down the length of the observation section along longitudinal transects. The sonar recorded the bed topography at a spatial resolution of $1 \mathrm{~cm}$ and with a vertical accuracy of $1 \mathrm{~mm}$ or about $2.7 D_{50}$.

[17] We measured bed topographic evolution for two water discharges: $40 \mathrm{~L} / \mathrm{s}$ and $80 \mathrm{~L} / \mathrm{s}$. Data were collected after the bed had reached a dynamic steady state, which was determined by constancy in the standard deviation of the bed topography in time. For a water discharge of $40 \mathrm{~L} / \mathrm{s}$, data of topographic evolution were collected at a temporal resolution of approximately $17 \mathrm{~s}$ along the $8 \mathrm{~m}$ longitudinal transect $A-A^{\prime}$ (shown in Figure 3). Figure 4a shows the streambed profiles at $1 \mathrm{~h}$ intervals for a water discharge of $40 \mathrm{~L} / \mathrm{s}$ and space-time plots of the sequential streambed profiles for the same discharge are shown at every $17 \mathrm{~s}$ in Figure 4c. For a water discharge of $80 \mathrm{~L} / \mathrm{s}$, data of topographic evolution were collected at a temporal resolution of approximately $45 \mathrm{~s}$ along two $6 \mathrm{~m}$ longitudinal transects $\left(B-B^{\prime}\right.$ and $C-C^{\prime}$ in Figure 3$)$ and along two $0.30 \mathrm{~m}$ lateral transects $\left(B-C\right.$ and $B^{\prime}-C^{\prime}$ in Figure 3$)$. Figure $4 \mathrm{~b}$ shows the streambed profiles at $1.5 \mathrm{~h}$ intervals for a water discharge of $80 \mathrm{~L} / \mathrm{s}$, and the space-time plot of the sequential streambed profiles for the same discharge are shown at every $45 \mathrm{~s}$ in Figure $4 \mathrm{~d}$. In the next section, we use the experimental topographic data to quantify the surface kinematics of bed form evolution for both the flows.

\section{Characteristics of Surface Kinematics}

[18] As discussed in section 2, the surface kinematics of bed form evolution is completely characterized by migration and deformation of the bed forms [McElroy and Mohrig, 2009]. In equation (1), the characteristic migration rate $V_{c}$ can be estimated by performing a cross-correlation analysis of the bed elevations along the streambed profiles at various time instances [McElroy and Mohrig, 2009]. However, this approach measures the bulk migration rate of all the bed forms present along a given profile. Our goal here is to clearly demarcate the translational component of surface kinematics from the deformation component, which is associated only with the change in shape of the bed forms rather than the differential migration rates of various bed forms along a streambed profile. To achieve this goal, we first detrended the streambed profiles by removing the mean bed elevation and a slight downstream shallowing and then computed the instantaneous migration rate at each point of the streambed profile as

$$
V(x, t)=-\frac{\Delta \eta(x, t) / \Delta t}{\Delta \eta(x, t) / \Delta x}
$$

where $\Delta \eta(x, t) / \Delta t$ denotes the rate of temporal change in elevation and $\Delta \eta(x, t) / \Delta x$ denotes the local slope, both computed via central differencing. To avoid singularities in the computed instantaneous migration rates, we neglected the data points that had an absolute value of local slope less than 0.01 , which comprised less than $10 \%$ of the data set.

[19] Once we had estimated the instantaneous migration rates at each point in space and time of the bed form evolution, we extracted the bed forms along all the time snap shots of the streambed profile. We used a simple peak detection algorithm to identify the crests and troughs of each of the bed forms. The bed elevation at each point along the streambed profile was compared to the bed elevation of its immediate neighbors (upstream and downstream). A point along the streambed profile was chosen to be a crest (or trough) of a bed form if the bed elevation at that point was greater (or lower) than the bed elevation of its immediate neighbors by a fixed value. We found that a fixed value of one fourth of the standard deviation of the bed elevations along a streambed profile did a good job of identifying bed forms while rejecting noise in the data. Figure 5 shows a sample streambed profile along with the extracted bed form crests and troughs for the experimental run with a water discharge of $80 \mathrm{~L} / \mathrm{s}$. The length of a bed form, $l_{b f}$, was defined as the longitudinal streamwise distance between two consecutive troughs, and the bed form height, $h_{b f}$, was defined as the difference between bed elevations of consecutive crests and troughs.

[20] We then defined the time scale of migration, $T_{m}$, as the ratio of the average bed form length to the space-time

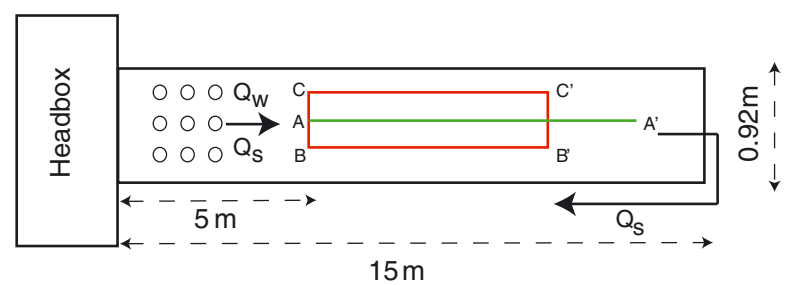

Figure 3. Schematic of the plan view of the experiment. For the water discharge of $40 \mathrm{~L} / \mathrm{s}$, data of bed elevation evolution were collected along the transect $A-A^{\prime}$ at an approximate temporal resolution of $17 \mathrm{~s}$ (green line). For the water discharge of $80 \mathrm{~L} / \mathrm{s}$, data of bed elevation evolution were collected along two parallel longitudinal transects $\left(B-B^{\prime}\right.$ and $\left.C-C^{\prime}\right)$ and two parallel lateral transects $\left(B-C\right.$ and $\left.B^{\prime}-C^{\prime}\right)$ at an approximate resolution of $45 \mathrm{~s}$ (red lines). 

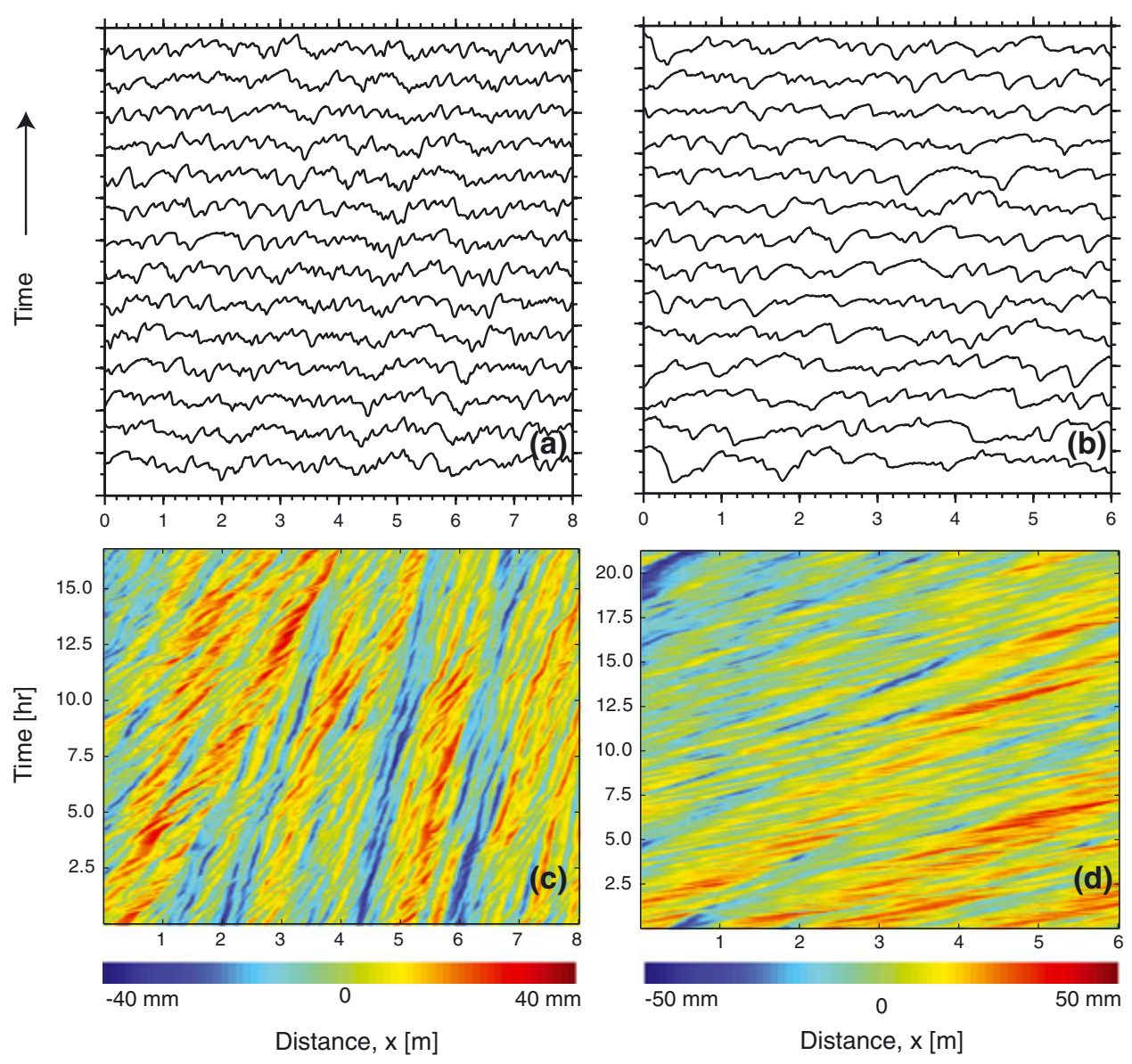

Figure 4. Sequential detrended streambed profiles, shown every $1 \mathrm{~h}$ and $1.5 \mathrm{~h}$ for water discharge of (a) $40 \mathrm{~L} / \mathrm{s}$ and (b) $80 \mathrm{~L} / \mathrm{s}$, respectively, with vertical offset to allow visualization. Space-time plot of sequential streambed profiles shown every $17 \mathrm{~s}$ and $45 \mathrm{~s}$ for water discharge of (c) $40 \mathrm{~L} / \mathrm{s}$ and (d) $80 \mathrm{~L} / \mathrm{s}$, respectively. The color bars indicate the elevation values of the detrended streambed profiles with bed form crests and troughs in red and blue colors, respectively.

average of the instantaneous migration rate, i.e.,

$$
T_{m}=\frac{\left\langle l_{b f}\right\rangle}{\left\langle\langle V(x, t)\rangle_{t}\right\rangle_{x}}
$$

The time scale of migration quantifies the average time it takes for a bed form to translate a distance equal to the average bed form length. We then computed the bed form averaged migration rate, $V_{b f}(x, t)$, by averaging the instantaneous migration rate, $V(x, t)$ (estimated using equation (5)), over the bed form length at each time instant and then time averaging over a nonoverlapping time window equal to the migration time scale, $T_{m}$, i.e.,

$$
V_{b f}(x, t)=\left\langle\langle V(x, t)\rangle_{l_{b f}}\right\rangle_{T_{m}}
$$

This exercise yielded the bed form averaged migration rate at each point in space and time.

[21] The instantaneous deformation rate was subsequently estimated using a discrete form of equation (1) given by

$$
\Pi(x, t)=\frac{\Delta \eta(x, t)}{\Delta t}+V_{b f}(x, t) \frac{\Delta \eta(x, t)}{\Delta x}
$$

[22] This quantity $\Pi(x, t)$ denotes the instantaneous deformation rate corresponding to the spatial and temporal resolution at which the above equation is applied, i.e., the spatial and temporal resolution at which experimental data were collected. In order to quantify the amount of deformation that a bed form experienced in the time that the bed form translated by one wavelength $\left\langle l_{b f}\right\rangle$, we computed the net deformation rate at each point along a bed form by averaging the instantaneous deformation rate over the migration time scale, $T_{m}$, i.e.,

$$
\Pi_{b f}=\langle\Pi(x, t)\rangle_{T_{m}}
$$

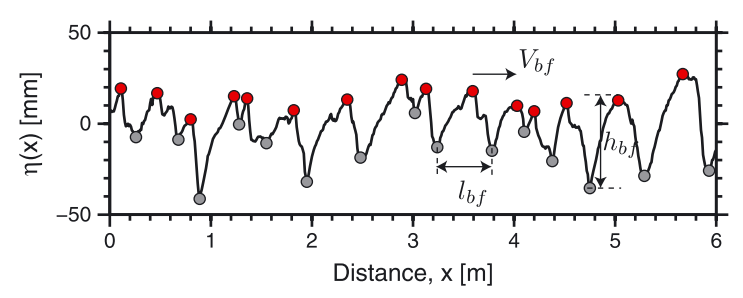

Figure 5. A sample detrended, mean-removed streambed profile during the experimental run with a water discharge of $80 \mathrm{~L} / \mathrm{s}$. The extracted bed form crests and troughs are indicated by red and gray circles, respectively. Also defined in the above plot is the length and height of a bed form. 


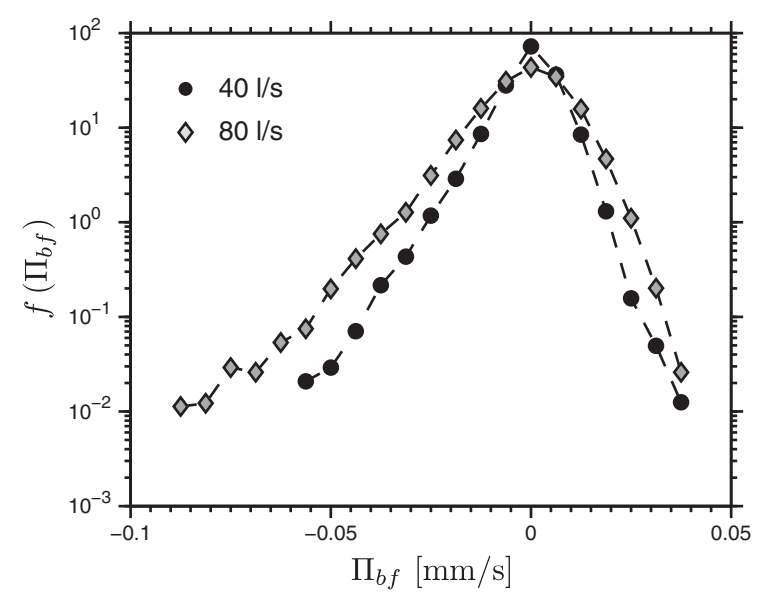

Figure 6. Relative frequency of the computed deformation rates $\Pi_{b f}$ in semilog scale for water discharge of $40 \mathrm{~L} / \mathrm{s}$ (black circles) and $80 \mathrm{~L} / \mathrm{s}$ (gray diamonds). Notice the linear nature of the tails in this semilog plot, which correspond to an exponential decay.

[23] In essence, if we were to treat a single bed form as an object, the bed form averaged migration rate $V_{b f}$ describes the rate at which this object translates (which is locally constant), and the net deformation rate $\Pi_{b f}$ describes the rate at which each point on this object changes its elevation relative to elevations of other points on the bed form in the time this object translated by its own length. Figure 6 shows the empirical distributions of the estimated deformation rates $\Pi_{b f}$ for the experimental runs with a water discharge of $40 \mathrm{~L} / \mathrm{s}$ (black circles) and $80 \mathrm{~L} / \mathrm{s}$ (gray diamonds). The estimated means of the deformation rates for both flows were approximately zero, confirming that the bed was neither aggrading nor degrading on average (see Table 1 for a summary of the estimated statistics of surface kinematics). The probability density functions (PDFs) of the estimated deformation rates exhibit exponential tails for both discharges (see Figure 6).

[24] To measure the competition between the deformation and migration of bed forms, we computed a deformation time scale, defined as

$$
T_{d}=\frac{\left\langle h_{b f}\right\rangle}{\left\langle\langle|\Pi(x, t)|\rangle_{x}\right\rangle_{t}}
$$

where $T_{d}$ is the deformation time scale and $h_{b f}$ is the bed form height. This time scale quantifies the average time it takes

Table 1. Estimated Statistics of the Surface Kinematics of Bed Form Evolution ${ }^{\mathrm{a}}$

\begin{tabular}{lcc}
\hline Quantity & Water Discharge, $40 \mathrm{~L} / \mathrm{s}$ & Water Discharge, $80 \mathrm{~L} / \mathrm{s}$ \\
\hline$V_{b f}(\mathrm{~mm} / \mathrm{s})$ & $0.092 \pm 0.013$ & $0.26 \pm 0.01$ \\
$\Pi_{b f}(\mathrm{~mm} / \mathrm{s})$ & $-1.67 \times 10^{-4} \pm 0.071$ & $-1.2 \times 10^{-3} \pm 0.011$ \\
$\mid \Pi_{b f}(\mathrm{~mm} / \mathrm{s})$ & $0.005 \pm 0.0014$ & $0.008 \pm 0.0072$ \\
$l_{b f}(\mathrm{~cm})$ & $22.7 \pm 8.9$ & $32.5 \pm 15.0$ \\
$h_{b f}(\mathrm{~mm})$ & $19.7 \pm 10.0$ & $22.7 \pm 13.0$ \\
$T_{m}($ mins $)$ & 41.2 & 20.8 \\
$T_{d}$ (mins) & 65.7 & 47.3 \\
\hline
\end{tabular}

${ }^{a}$ The temporal resolution of the data is approximately $17 \mathrm{~s}$ and $45 \mathrm{~s}$ for $40 \mathrm{~L} / \mathrm{s}$ and $80 \mathrm{~L} / \mathrm{s}$ flows, respectively.

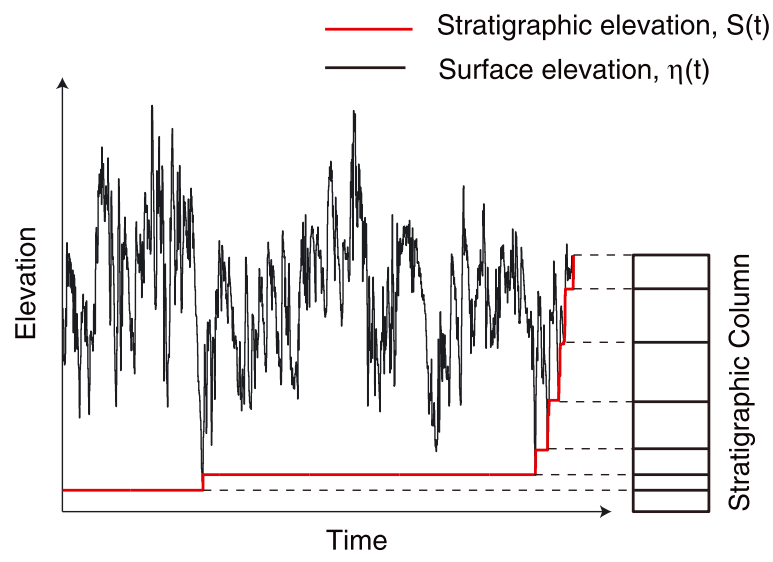

Figure 7. A schematic showing the building of a stratigraphic column $(S(t)$, red line) from the elevation time series $(\eta(t)$, black line). Stratigraphic deposits are depositional bodies bound between two erosional events.

for a bed form to completely lose memory of its shape. If the deformation time scale and the migration time scale are comparable, then the bed form "forgets" its shape in the time over which it translates one wavelength. Table 1 summarizes the computed migration and deformation time scales for both the experimental runs. We note that in our experimental runs, the bed forms lose the memory of their shape by the time they translate one to two wavelengths (i.e., $T_{d} \approx 1-2 T_{m}$ ).

[25] As stated in section 2 (equations (2) and (4)), for deposits of transverse, unidirectional bed forms the local slope and curvature of the stratigraphic boundary record the competition between migration and deformation of the evolving bed forms. We have extracted the relevant quantities (migration and deformation) of surface kinematics of the experimental bed forms required for our theoretical predictions. The prediction of the local slope of the stratigraphic boundary at each point with no net deposition (as in the experimental case) is

$$
S_{s t}=\frac{\Pi_{b f}}{V_{b f}}
$$

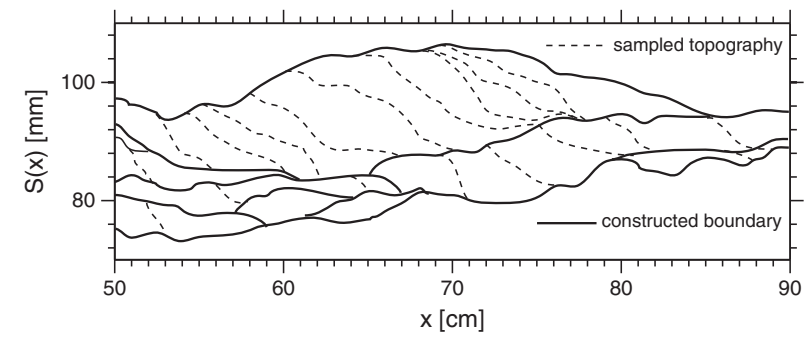

Figure 8. Constructed preserved stratigraphy for a $0.4 \mathrm{~m}$ longitudinal section from the $40 \mathrm{~L} / \mathrm{s}$ experimental run. Two distinct features can be observed in the preserved stratigraphy, namely, the constructed boundaries (solid lines) and the sampled topography (dashed lines). Constructed boundaries are surfaces that are preserved, which are not present during the topographic evolution, whereas the sampled topography corresponds to the record of migrating lee faces of the bed forms. 
The predicted local curvature of the bounding surfaces can be obtained by taking the first spatial derivative of equation (11):

$$
C_{s t}=\frac{\partial S_{s t}}{\partial x}=\frac{1}{V_{b f}} \frac{\partial \Pi_{b f}}{\partial x}
$$

In the next section, we construct the stratigraphy from the elevation time series for both the experimental runs and extract the statistics of the geometrical structure of the stratigraphic boundaries for comparison with the theory.

\section{Geometrical Structure of the Preserved Stratigraphy}

[26] The preserved stratigraphic column can be reconstructed from the elevation time series (Figure 7). We constructed the stratigraphic columns at each point along the streambed profile using the data of elevation time series collected during the experimental runs (see Ganti et al. [2011] and Straub et al. [2012] for other examples of this method). Figure 8 shows the 2-D structure of the preserved stratigraphy for a $0.4 \mathrm{~m}$ longitudinal section for the experiment with water discharge of $40 \mathrm{~L} / \mathrm{s}$. Two distinct features of the 2-D preserved stratigraphy are the constructed boundaries (solid lines in Figure 8) and the sampled topography (dashed lines in Figure 8). Constructed boundaries are surfaces that are preserved in the stratigraphic record but that never existed as topography. On the other hand, sampled topography is preserved surface topography; here this is mostly migrating lee faces. Our first goal in this section is to distinguish these two features in the deposit since they represent fundamentally different mechanisms of stratal creation.

[27] Because they arise from lee-face preservation, sampled topographic surfaces in our preserved stratigraphy have relatively steep slopes (near the angle of repose) and nearzero curvature. Also of importance is the time of preservation of these surfaces. A single sampled topographic surface in the stratigraphic record forms on a time scale much less than the migration time scale $T_{m}$ since each one represents an instantaneous lee face of the migrating bed form. The surfaces that correspond to the sampled topography are bounded by the constructed boundaries in the preserved stratigraphy (i.e., bounding surfaces in the sense of Brookfield [1977]). Thus, on average, the constructed boundaries are created over a time scale equivalent to the time scale of migration. We used the time of preservation to delineate the constructed boundaries from the sampled topography in the 2-D stratigraphy. Thus, to identify the constructed 2-D stratigraphy (for example, see Figure 9a), we kept the surfaces that were at least $T_{m}$ min apart in their preservation and eliminated the rest. As seen from visual inspection in Figure $9 \mathrm{~b}$, this method yielded the constructed boundaries and removed almost all of the preserved lee faces of the migrating bed forms.

[28] The constructed boundaries of the preserved stratigraphy are noisy, with millimeter-scale fluctuations (Figure 9b) that reflect observational noise and are not present on the actual bounding surfaces. To remove this noise, we must smooth the constructed stratigraphy, for example, by using a moving-average filter. However, a moving average would have the undesirable effect of not preserving local features in the stratigraphic boundaries (instead, it spreads (dilates) them because equal weight is
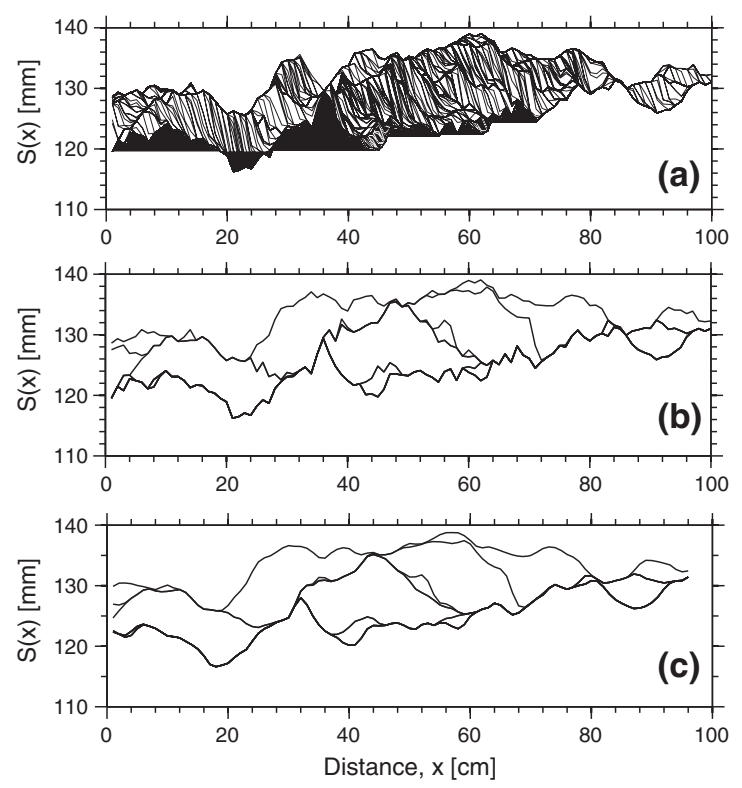

Figure 9. (a) Constructed 2-D structure of preserved stratigraphy for a $1 \mathrm{~m}$ section of the longitudinal transect $B-B^{\prime}$ (see Figure 3) for the experimental run with a water discharge of $40 \mathrm{~L} / \mathrm{s}$. (b) The constructed boundaries, delineated using the time separation between the preserved surfaces corresponding to the average time of migration of the bed forms, in the 2-D structure of the preserved stratigraphy. (c) Constructed boundaries smoothed using a local Gaussian filter of length equal to a quarter of the mean bed form length. Notice that the smoothing operation removes the millimeter-scale noise present in the constructed boundaries.

given to both the point of interest and the points around it). To remove the noise while preserving the local shape of the surfaces, we used a Gaussian window filter, $G(L)$. This filter gives maximum weight to the point of interest and progressively lower weights to the surrounding points. Since the average length of the preserved cross sets was documented to be half of the mean bed form length [Allen, 1973; Leclair, 2002], we chose the length scale of our filtering to be a quarter of the mean bed form length, i.e., $L=\left\langle l_{b f}\right\rangle / 4$ (which corresponds to half the average length of the cross sets). Further, we can take advantage of the well-known property of the convolution product,

$$
\frac{\partial(S \star G)}{\partial x}=G \star \frac{\partial S}{\partial x}=\frac{\partial G}{\partial x} \star S
$$

which implies that smoothing the stratigraphic boundary $S$ with a kernel $G$ and then taking the derivative (left most term) is equivalent to taking derivatives of the stratigraphic boundary and smoothing these derivatives with the kernel $G$ (middle term), or equivalent to smoothing the stratigraphic boundary directly with the derivative of the kernel $G$ (rightmost term), in computing the slope and curvature of bounding surfaces of the cross sets. Since the derivatives of the Gaussian filter are proper wavelets, we can use wavelet filtering techniques to compute the slope and curvature of the stratigraphic boundaries at the given scale [e.g., Lashermes et al., 2007]. 

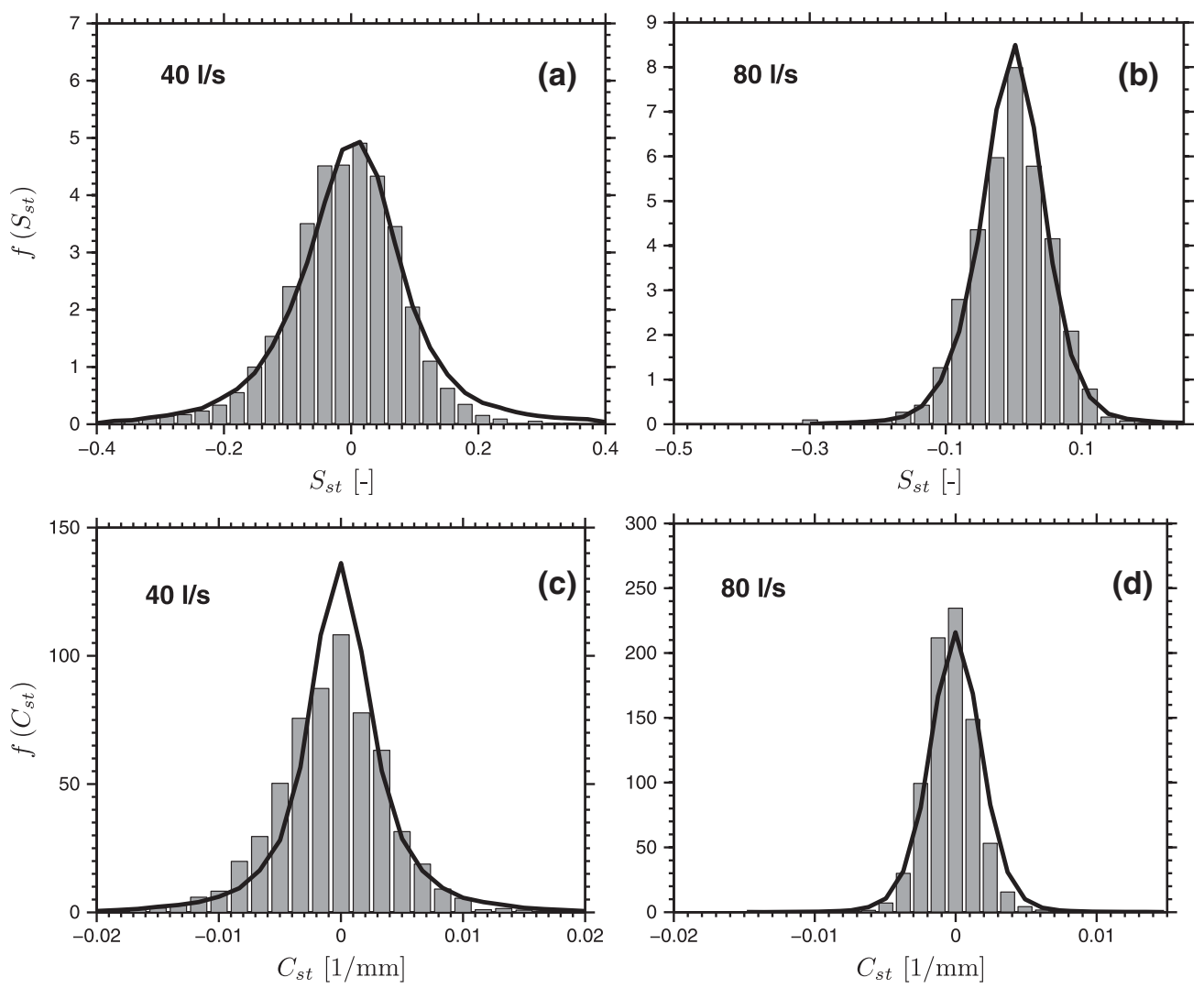

Figure 10. Plot showing the empirical (gray bars) and the theoretically predicted (solid line) densities of the (a, b) local slopes and (c, d) curvatures of the stratigraphic boundaries for both the $40 \mathrm{~L} / \mathrm{s}$ and $80 \mathrm{~L} / \mathrm{s}$ experimental runs. The observed slopes and curvatures were computed as the first and second derivatives of the smoothed stratigraphic boundaries, respectively. The predicted slopes and curvatures of the stratigraphic boundaries were computed using equations (11) and (12), respectively.

\section{Results}

[29] In section 5, we delineated the constructed boundaries from the sampled surfaces in the preserved stratigraphy and then smoothed the constructed boundaries with a Gaussian window filter. We then computed the first and second derivatives of the smoothed data to get the local slope and curvature of these surfaces, respectively (first term of equation (13)). Figure 10 shows the empirical densities (gray bars) of the observed slopes $\left(S_{s t}\right)$ and curvatures $\left(C_{s t}\right)$ of the constructed boundaries in the preserved stratigraphy for both $40 \mathrm{~L} / \mathrm{s}$ and $80 \mathrm{~L} / \mathrm{s}$ discharges. In this section, we compare the observed statistics of the geometrical structure of the stratigraphic boundaries with the theoretical predictions of equations (11) and (12).

[30] We computed the predicted slope of the bounding surfaces of the preserved cross sets by evaluating equation (11) using the experimental data collected for both flows. For computing the predicted curvature of the bounding surfaces, we first computed the spatial gradient of net deformation rate $\left(\Pi_{b f}\right)$ via central differencing and then evaluated equation (12) using our experimental data. Figure 10 shows the densities of the predicted slope and curvature of the bounding surfaces of the preserved cross sets for both the $40 \mathrm{~L} / \mathrm{s}$ and $80 \mathrm{~L} / \mathrm{s}$ experimental runs. It is evident that equations (11) and (12) provide a very good approximation of the observed slope and curvature of the stratigraphic boundaries. We performed the KolmogorovSmirnov two-sample test to check if both the samples of the observed and predicted quantities of slope and curvature of the stratigraphic boundaries came from the same underlying continuous distribution [Massey, 1951]. The test statistic is the maximum of the absolute value of the distance between the two-sample cumulative distribution functions (CDFs). The null hypothesis is that both the samples come from the same underlying continuous distribution; it is rejected if the maximum of the absolute value of the distance between the two-sample CDFs $\left(D_{C D F}\right)$ is greater than some threshold value $\left(D_{\alpha_{1}}\right)$. This threshold value, for large sample sizes, is given by

$$
D_{\alpha_{1}}=c\left(\alpha_{1}\right) \sqrt{\frac{n_{1}+n_{2}}{n_{1} \times n_{2}}}
$$

where $\alpha_{1}$ is the significance level, $n_{1}$ and $n_{2}$ are the sample sizes, and $c\left(\alpha_{1}\right)$ is a coefficient, which comes from the Kolmogorov distribution tables. Figure 11 shows the absolute values of the distance between the observed and predicted CDFs of the slope and curvature of the stratigraphic boundaries along with the threshold of acceptance of the null hypothesis in the Kolmogorov-Smirnov test at a significance level of 5\%. From Figures 11a and 11b, we conclude that the observed and predicted slopes of the stratigraphic 

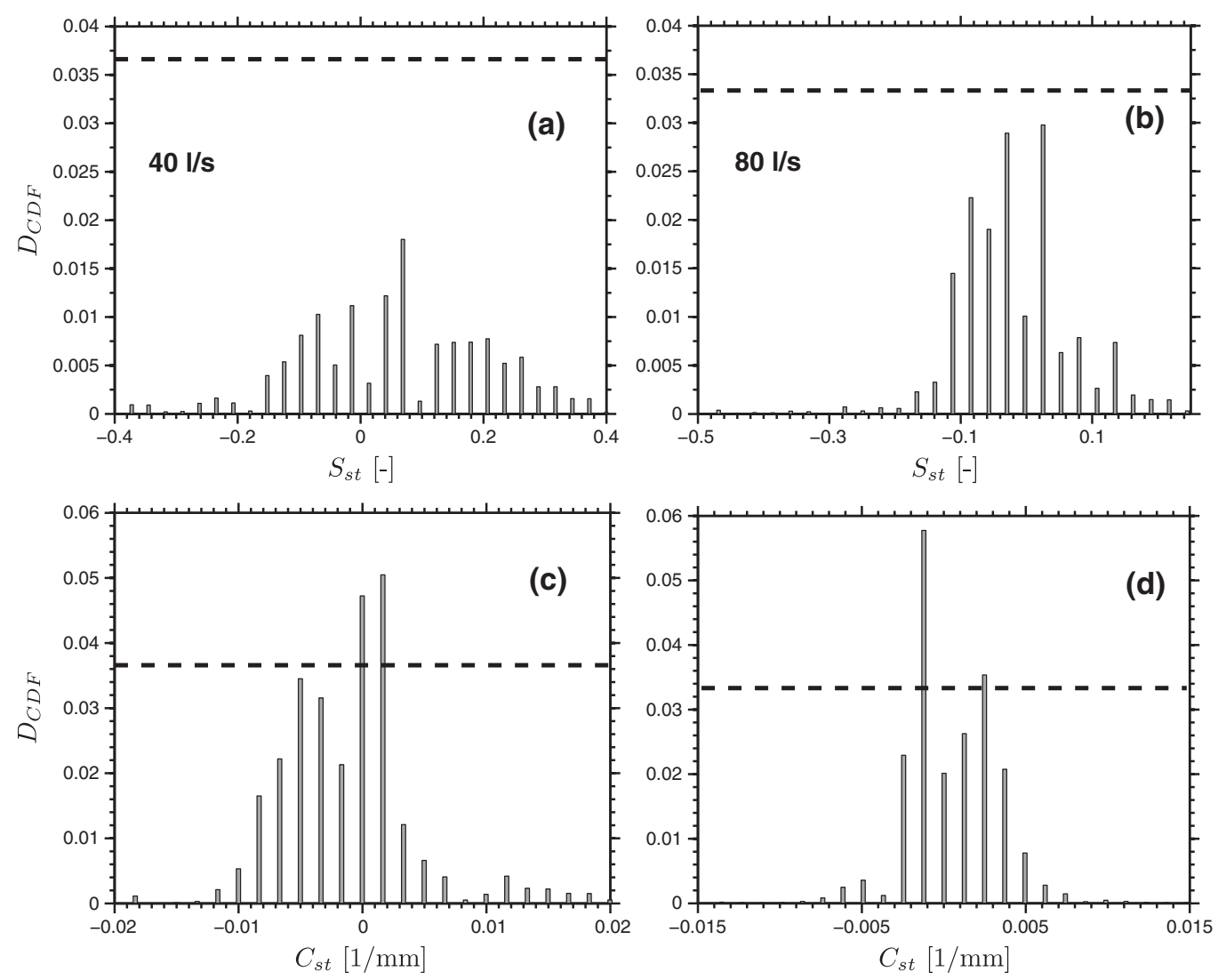

Figure 11. The absolute value of the distance between the two-sample CDFs of (a, b) slopes and (c, d) curvatures of the stratigraphic boundaries along with the threshold value (dashed line) of acceptance for the Kolmogorov-Smirnov test at a significance level of 5\%.

boundaries have the same underlying continuous distribution as $D_{C D F}<D_{\alpha_{1}}$. Thus, equation (11) is effective in relating the characteristics of bed form surface kinematics to the slopes of the stratigraphic boundaries. Figures $11 \mathrm{c}$ and $11 \mathrm{~d}$ indicate that the distance between the sample CDFs of the observed and predicted curvature of the stratigraphic boundaries exceeds the threshold value at a significance level of 5\%, which could cause us to reject the null hypothesis. However, we note that the values of $D_{C D F}$ exceed the threshold $D_{\alpha_{1}}$ at curvatures that are very close to zero. We believe that this is a direct effect of the resolution of the data collected. The vertical and streamwise resolution of the data collected were $1 \mathrm{~mm}$ and $1 \mathrm{~cm}$, respectively, indicating that local curvature values very close to zero are not resolved very well in this data set. Except at values of local curvature very close to zero, the distance between the two-sample CDFs of the observed and predicted curvatures of the stratigraphic boundaries is well within the threshold value of $D_{\alpha_{1}}$, indicating that the predicted curvature of the stratigraphic boundaries computed using equation (12) provides a good approximation of the observed PDF of the local curvature of the stratigraphic boundaries.

[31] We also compared the statistics (mean and standard deviation) of the absolute values of the observed and predicted slope $\left|S_{s t}\right|$ and curvature $\left|C_{s t}\right|$ of the stratigraphic boundaries. Figure 12 shows that both the mean and standard deviation of the geometrical properties of the stratigraphic boundaries are well described by equations (11) and (12). All in all, we conclude that bed form deformation is important in setting the geometrical structure of the stratigraphic boundaries. The ratio of deformation rate and the migration rate sets the slope of the stratigraphic

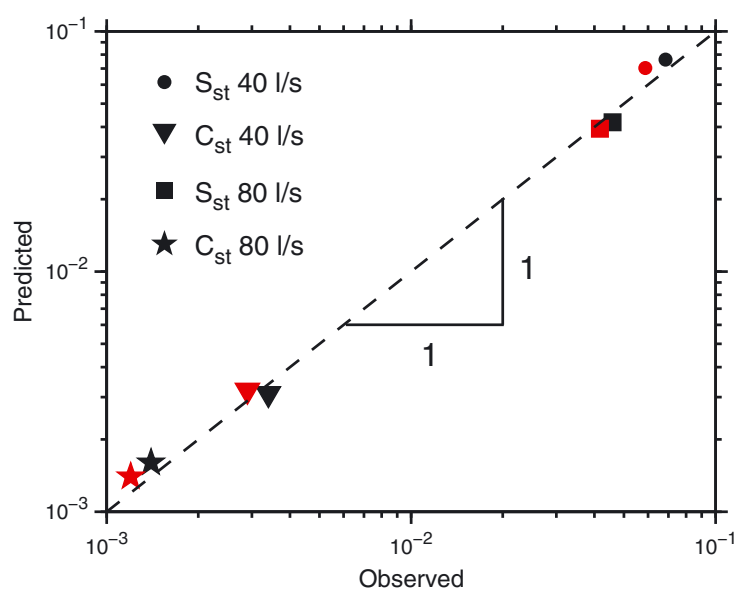

Figure 12. Plot showing the comparison of the mean (black markers) and standard deviation (red markers) of the absolute value of the observed and predicted slope and curvature of the stratigraphic boundaries for both $40 \mathrm{~L} / \mathrm{s}$ and $80 \mathrm{~L} / \mathrm{s}$ experimental runs. 

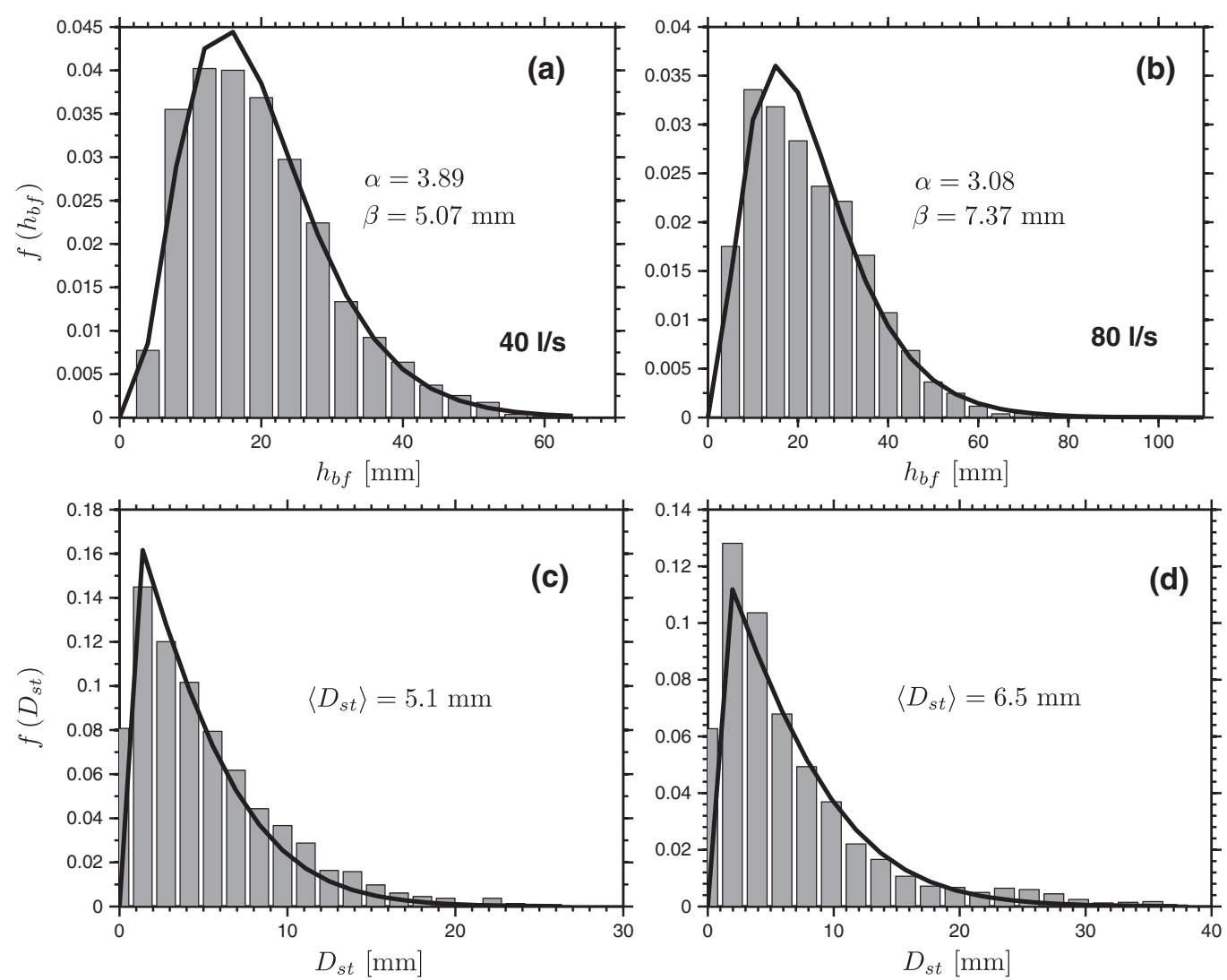

Figure 13. (top panels) Plots showing the empirical densities (gray bars) of the extracted bed form heights along with the best fit two-parameter Gamma distribution (solid line) for $40 \mathrm{~L} / \mathrm{s}$ and $80 \mathrm{~L} / \mathrm{s}$ experimental runs. (bottom panels) Observed empirical densities (gray bars) of the set thicknesses computed from the constructed preserved stratigraphy for the experimental runs. Also shown is the predicted set thickness distribution (solid line) based on the variability of bed form heights computed using equation (16) with $a=2 / \beta$ [Paola and Borgman, 1991].

boundaries, and the ratio of the spatial gradient of the deformation rate and the migration rate determine the curvature of the boundaries.

\section{Discussion}

[32] As shown in the previous section, the surface kinematics of the bed form evolution can be statistically mapped into the geometrical structure of the bounding surfaces of the preserved cross sets. The set thickness distribution $f\left(D_{s t}\right)$, along with the length, slope, and curvature of the stratigraphic boundaries, provide a comprehensive statistical description of the geometry of the preserved strata. Under zero net deposition, Paola and Borgman [1991] derived an analytical relationship between the variability of the bed form heights $h_{b f}$ and the distribution of set thickness $D_{s t}$. They used a two-parameter Gamma distribution given by

$$
f\left(h_{b f}\right)=\frac{h_{b f}^{\alpha-1} \exp \left(-h_{b f} / \beta\right)}{\beta^{\alpha} \Gamma(\alpha)}
$$

where $\alpha$ is the shape parameter and $\beta$ is the scale parameter of the Gamma distribution to describe the pdf of the bed form heights. (Note that the main purpose of using the Gamma distribution was to capture the exponential tail of the pdf of bed form height). They analytically derived set thickness distribution, under the assumptions of zero net deposition and an exponential tail for the PDF of bed form heights, for $D_{s t}>0$ to be

$$
f\left(D_{s t}\right)=\frac{a e^{-a D_{s t}}\left(e^{-a D_{s t}}+a D_{s t}-1\right)}{\left(1-e^{-a D_{s t}}\right)^{2}}
$$

and zero for $D_{s t} \leq 0$, where $a=2 / \beta$ [Paola and Borgman, 1991]. Figure 13 shows that the bed form heights were well described by a two-parameter Gamma distribution, and equation (16) indeed provides a good description of the resulting set thickness distribution. Thus, our experimental data are also in good agreement with the theory of Paola and Borgman [1991]. The bed form heights together with the lengths of the bed forms determine the set thickness distribution and the length distribution of the cross sets for deposits of transverse, unidirectional bed forms [e.g., Leclair, 2002].

[33] Our results in the previous section show that the slope and curvature of the stratigraphic boundaries record the competition between the deformation and migration of the bed forms. We note that the mean and standard deviation of the deformation rate change at a much slower rate with discharge changes, when compared to the migration rate (see Table 1). Thus, the numerator in the right-hand side (deformation rate and gradient of deformation rate) of equations (11) and (12) does not change at the same rate with 
the flow as the denominator (migration rate). This results in higher variability in slope and curvature of the stratigraphic boundaries at lower flows compared to those at higher flows (see Figure 10). This is also reflected in the higher values of the mean and standard deviation of the absolute values of the slope and curvature of the stratal boundaries at the lower experimental water discharge compared to those at the higher discharge (see Figure 12).

[34] Further, gradual changes in the migration rate and the aggradation rate of the bed forms are also recorded in the geometrical structure of the stratal boundaries (see equations (2) and (3)). We note that a large-scale curvature (corresponding to a scale much larger than the length scale of the bed forms) can be imposed on the stratigraphic boundaries if there is a gradual change in the migration rate or the net aggradation rate in the system. According to equation (3), this effect should be recorded in the curvature of the stratigraphic boundaries (see Hunter [1977b] and Rubin [1987] for examples of this large-scale curvature). This implies that multiscale analysis of curvature of stratigraphic boundaries has the potential to delineate not only the effect of bed form deformation but also the changes in migration speed and aggradation rate that might result from larger-scale changes in the system.

[35] We note that there could be several confounding factors that would limit the applicability of our proposed theory. The theory is directly applicable to transverse, unidirectional bed forms, where our one-dimensional treatment holds true. However, when the bed forms are not perfectly transverse, the lateral migration component (along-crest transport) of the bed forms can play an important role. For example, if scour pits in dune troughs migrate along crest, when they pass through a plane perpendicular to the crest line (or through a plane parallel to the flow), they will create a trough-shaped lower bounding surface without any changes in the shape of the bed forms or net deposition rate. Another complicating effect is when the primary direction of migration of the bed forms is oblique to the flow direction. In fluvial settings, for example, this can happen when flow rotates around a point bar [e.g., Dietrich and Smith, 1983] (with flow direction changing faster than bed forms can adjust) or when the flow varies systematically along the crests of the bed forms (for example, due to slower flow near the bank). Either case can result in scour pits in the bed form troughs that do not migrate perpendicular to the main crests (see Rubin [1987] for examples). In such cases, the morphology along a single streamwise profile varies through time, although the overall topography might be shifting obliquely to the flow direction. Finally, outcrop orientation affects measured set-boundary slope and curvature; even flat set boundaries may appear curved if the outcrop is not perpendicular to the bed form crests.

\section{Conclusion}

[36] Quantitative relationships between preserved stratigraphy and bed form surface kinematics together with information about the environmental conditions that control surface kinematics would be a step toward more detailed reconstruction of paleoenvironmental conditions from the stratigraphic record. In this paper, we developed a theoretical framework to quantitatively relate surface kinematics of subaqueous, transverse bed forms to the geometry of the bounding surfaces of the preserved strata and used experimental measurements of bed form evolution to test the theory. We conclude that:

[37] 1. In the absence of net deposition, the local slope of the stratigraphic boundaries $S_{s t}$ is equal to the ratio of the deformation rate of the bed forms $\Pi_{b f}$ to the migration rate of the bed forms $V_{b f}$ (equation (11)). The deformation rate quantifies the change in shape of the bed forms, while the migration rate quantifies the rate of translation of the bed forms. These measures of bed form surface kinematics should be computed via appropriate averaging over a time scale comparable to the migration time scale, $T_{m}$.

[38] 2. The curvature of the stratigraphic boundaries $C_{s t}$, defined as the first spatial derivative of the local slopes of the stratigraphic boundaries, is equal to the ratio of the spatial gradient of the deformation rate and the migration rate of the evolving bed forms (equation (12)).

[39] 3. The deformation rate increases more slowly with discharge than the migration rate does, implying that under low flow conditions the slope and curvature of the stratigraphic boundaries exhibit higher variability than under higher flows.

[40] 4. The theoretical predictor of the curvature of the stratigraphic boundaries (equation (3)) suggests that a multiscale analysis of the curvature of the stratigraphic boundaries has the potential to provide information not only about the deformation but also about any large-scale changes in migration rate and/or aggradation rate.

[41] 5. The experimental data on set thickness distribution were consistent with the theory of Paola and Borgman [1991], with the bed form heights being well described by a two-parameter Gamma distribution and the set thickness distribution being well approximated with the theoretical PDF of equation (16).

\section{Notation}

$x$ streamwise distance.

$t$ time.

$\eta(x, t)$ bed elevation.

$V_{c}$ characteristic migration rate.

$V(x, t)$ instantaneous migration rate computed at highest space and time resolution.

$V_{b f}(x, t)$ bed form migration rate averaged over each bed form length scale and migration time scale.

$T_{m}$ migration time scale.

$T_{d}$ deformation time scale.

$\Pi(x, t)$ instantaneous deformation rate.

$\Pi_{b f}(x, t)$ net deformation rate averaged over the migration time scale.

$S(x) \quad$ stratigraphic surface elevation.

$S_{s t}$ local slope of the bounding surfaces of the preserved cross set.

$C_{s t}$ local curvature of the bounding surfaces of the preserved cross set.

$h_{b f}$ bed form height.

$l_{b f}$ bed form length.

$G(L) \quad$ Gaussian window filter of length $L$.

$D_{s t}$ set thickness.

$D_{C D F}$ absolute value of the distance between observed and predicted CDF. 


\section{$\alpha$ power-law parameter of the Gamma distribution. \\ $\beta$ exponential parameter of the Gamma distribution. \\ $\bar{r}$ net aggradation rate. \\ $\alpha_{1}$ significance level for the Kolmogorov-Smirnov test. \\ $D_{\alpha_{1}}$ threshold for acceptance of null hypothesis in the Kolmogorov-Smirnov test. \\ $a$ parameter of the Paola-Borgman pdf of set thickness.}

[42] Acknowledgments. This research was supported by the National Center for Earth-surface Dynamics (NCED), a Science and Technology Center funded by NSF under agreement EAR-0120914, and also by NSF grants EAR-0824084 and EAR-0835789. E.F.G. would like to acknowledge funds from the Joseph T. and Rose S. Ling Professorship. V.G. acknowledges the support from the Hydrology Section of AGU via the Horton Research Grant. We would like to thank Andy Petter for stimulating discussions that improved the ideas presented in this manuscript and Raleigh Martin for the help in conducting the experiment. We also thank Alex Densmore, Dave Rubin, and an anonymous reviewer for constructive reviews on an earlier version of this manuscript.

\section{References}

Ager, D. V. (1973), The Nature of the Stratigraphic Record, Wiley, New York.

Allen, J. R. L. (1963a), Asymmetrical ripple marks and the origin of waterlaid cosets of cross-strata, Lpool Machr. Geol. J., 3, 187-236.

Allen, J. R. L (1963b), The classification of cross-stratified units with notes on their origin, Sedimentology, 2, 93-114.

Allen, J. R. L. (1968), Current Ripples: Their Relations to Patterns of Water and Sediment Motion, North Holland Pub. Co., Amsterdam.

Allen, J. R. L. (1970), A quantitative model of climbing ripples and their cross-laminated deposits, Sedimentology, 14, 5-26.

Allen, J. R. L. (1973), Features of cross-stratified units due to random and other changes in bed forms, Sedimentology, 20, 189-202.

Allen, P. A. (2008), Time scales of tectonic landscapes and their sediment routing systems, in Landscape Evolution: Denudation, Climate and Tectonics Over Different Time and Space Scales, edited by Gallager, K., S. J. Jones, and J. Wainwright, Prentice-Hall, Englewood Cliffs, N.J., pp. $7-28$.

Anderson, R. S., and K. L. Bunas (1993), Grain size segregation and stratigraphy in aeolian ripples modelled with a cellular automaton, Nature, 365, $740-743$.

Blom, A., J. S. Ribberink, and H. J. de Vriend (2003), Vertical sorting in bedforms: Flume experiments with a natural and trimodal sediment mixture, Water Resour. Res., 39(2), 1025, doi:10.1029/2001WR001088.

Bridge, J. S., and J. L. Best (1997), Preservation of planar laminae due to migration of low-relief bad waves over aggrading upper-stage plane beds: Comparison of experimental data with theory, Sedimentology, 44, 253-262.

Bridge, J. S., and R. S. Tye (2000), Interpreting the dimension of ancient channel bars, channels, and channel belts from wireline-logs and cores, AAPG Bull., 84, 1205-1228.

Brookfield, M. E (1977), The origin of bounding surfaces in ancient aeolian sandstones, Sedimentology, 24, 303-332.

Dietrich, W. E., and J. D. Smith (1983), Influence of the point bar on flow through curved channels, Water Resour. Res., 19(5), 1173-1192.

Ganti, V., K. M. Straub, E. Foufoula-Georgiou, and C. Paola (2011), Space-time dynamics of depositional systems: Experimental evidence and theoretical modeling of heavy-tailed statistics, J. Geophys. Res., 116 F02011, doi:10.1029/2010JF001893.

Hunter, R. E. (1977a), Terminology of cross-stratified sedimentary layers and climbing-ripple structures, J. Sed. Petrol., 47, 697-706.

Hunter, R. E. (1977b), Basic types of stratification in small eolian dunes, Sedimentology, 24, 361-387.

Jerolmack, D. J., and D. Mohrig (2005), Frozen dynamics of migrating bedforms, Geology, 33(1), 57-60.

Lashermes, B., E. Foufoula-Georgiou, and W. E. Dietrich (2007), Channel network extraction from high resolution topography using wavelets, Geophys. Res. Lett., 34, L23S04, doi:10.1029/2007GL031140.

Leclair, S. F. (2002), Preservation of cross-strata due to the migration of subaqueous dunes: An experimental investigation, Sedimentology, 49 1157-1180

Leclair, S. F., and J. S. Bridge (2001), Quantitative interpretation of sedimentary structures formed by river dunes, J. Sed. Res., 71, 713-716.

Leclair, S. F., J. S. Bridge, and F. Wang (1997), Preservation of cross-strata due to migration of subaqueous dunes over aggrading and non-aggrading beds: Comparison of experimental data with theory, Geosci. Can., 24, $55-66$.

Makse, H. A. (2000), Grain segregation mechanism in aeolian sand ripples, Eur. Phys. J. E, 1, 127-135.

Martin, R. L., and D. J. Jerolmack (2013), Origin of hysteresis in bedform response to unsteady flows, Water Resour. Res., 49, 1314-1333, doi:10.1002/wrcr.20093.

Massey, F. J. (1951), The Kolmogorov-Smirnov test for goodness of fit, $J$. Am. Stat. Assoc., 46(253), 68-78.

McElroy, B., and D. Mohrig (2009), Nature of deformation of sandy bed forms, J. Geophys. Res., 114, F00A04, doi:10.1029/2008JF001220.

Paola, C. (2000), Quantitative models of sedimentary basin filling, Sedimentology, 47, 121-178.

Paola, C., and L. Borgman (1991), Reconstructing random topography from preserved stratification, Sedimentology, 38, 553-565.

Paola, C., K. M. Straub, D. Mohrig, and L. Reinhardt (2009), The "unreasonable effectiveness" of stratigraphic and geomorphic experiments, Earth Sci. Rev., 97, 1-43.

Rubin, D. M. (1987), Cross-Bedding, Bedforms, and Paleocurrents: Concepts in Sedimentology and Paleontology, vol. 1, SEPM, Tulsa.

Rubin, D. M., and R. E. Hunter (1982), Bedform climbing in theory and nature, Sedimentology, 29, 121-138.

Sheets, B., T. A. Hickson, and C. Paola (2002), Assembling the stratigraphic record: Depositional patterns and time-scales in an experimental alluvial basin, Basin Res., 14, 287-301.

Sheets, B., C. Paola, and J. M. Kelberer (2007), Creation and preservation of channel-form sand bodies in an experimental alluvial basin, in Sedimentary Processes, Environments and Basins, edited by G. Nichols, E. Williams, and C. Paola, Blackwell Publishing, Oxford, U.K., pp 555-567.

Sorby, H. C. (1859), On the structure produced by the currents during the deposition of stratified rocks, Geologist, 2, 137-147.

Sorby, H. C. (1908), On the application of quantitative methods to the study of the structure and history of rocks, Q. H. Geol. Soc. Lond., 64, 171-233.

Storms, J. E. A., R. L. V. Dam, and S. F. Leclair (1999), Preservation of cross-strata due to migration of current ripples over aggrading and non-aggrading beds: Comparison of experimental data with theory, Sedimentology, 46, 189-200.

Straub, K. M., V. Ganti, C. Paola, and E. Foufoula-Georgiou (2012), Prevalence of exponential bed thickness distributions in the stratigraphic record: Experiments and theory, J. Geophys. Res., 117, F2, doi:10.1029/2011JF002034.

Strong, N., and C. Paola (2008), Valleys that never were: Time surfaces versus stratigraphic surfaces, J. Sed. Res., 78, 579-593.

Yalin, M. S. (1964), Geometrical properties of sand waves, J. Hydraul. Eng., 90, 105-119. 